Tompkins K.B., Martz D.M., Rocheleau C.A., Bazzini D.G. (2009) Social likeability, conformity, and body talk: Does fat talk have a normative rival in female body image conversations? Body Image: An International Journal of Research. 6 (4), pp. 292298.

Elsevier (ISSN: 1740-1445) doi:10.1016/j.bodyim.2009.07.005 - September 2009

Keywords: Fat talk | Conformity | Body talk | Self-acceptance

\title{
Social likeability, conformity, and body talk: Does fat talk have a normative rival in female body image conversations?
}

\author{
K. Brooke Tompkins, Denise M. Martz, Courtney A. Rocheleau, and Doris \\ G. Bazzini
}

\begin{abstract}
Fat talk, dialogues among women involving negative body-focused discussions, was studied as a function of conformity and social likeability through the use of four vignettes depicting young women in conversation. Using a 2 (body presentation style of the group: negative or positive) $\times 2$ (body presentation style of the target, Jenny: negative or positive) factorial design, 215 college women (92.1\% non-Hispanic Caucasian) read one of four vignettes in a classroom setting and made ratings on a social likeability scale. Participants' personal ratings of Jenny's likeability were higher when she spoke positively about her body, whereas they expected the other group members in the vignette to like Jenny more when she conformed to the group's body presentation style. This study is the first to support two competing norms for women's body image-the existing norm to fat talk versus a newly documented norm that some women like others who express body acceptance.
\end{abstract}




\section{Introduction}

Contemporary American culture places a high value on attractiveness, with a media that applauds men and women with thin, sculpted, and beautiful bodies. Women remain especially affected by society's emphasis on attractiveness and usually experience body dissatisfaction when comparing their bodies to the cultural ideal (Rodin, Silberstein, \& Striegel-Moore, 1984) and to their thin, attractive peers (Krones, Stice, Batres, \& Orjada, 2005). Cultural pressure to be physically attractive may be best personified by appearance-focused media images. The resulting negative impact of this emphasis on the thin ideal is often evidenced in the conversations of women that highlight preponderance toward dissatisfaction with one's body ([Clark and Tiggemann, 2006] and [Grogan et al., 1996]). Nichter and Vuckovic (1994) were the first researchers to examine discussions of weight between females, and termed these discussions "fat talk." They suggested that fat talk is usually heard in social groups of females of average weight, and is often used for impression management (Schlenker, 1985). Using ethnographic research, Nichter and Vuckovic (1994) found that middle school-aged females reported using fat talk to elicit social likeability, and so as not to appear arrogant and to avoid social rejection. Hence, these young females were reporting conformity pressure to fat talk. Nichter and Vuckovic did not document conversations of self-accepting body talk among these girls. Therefore, the current study sought to experimentally examine how conformity to fat talk, or its seemingly opposite form of dialog — positive body talk, affect social likeability in female conversations.

Recent research has revealed various social norms surrounding fat talk as it pertains to female social groups. Britton, Martz, Bazzini, Curtin, and LeaShomb (2006) presented male and female college-aged participants with a hypothetical fat talk discussion among females and subsequently asked them to identify the expected response of the target female in the conversation. They found that females expected other females to selfderogate when other women were engaging in a fat talk discussion. Furthermore, Gapinski, Brownell, and LaFrance (2003) conducted a study that focused on fat talk as a mode of objectification, in which female college-aged participants tried on either bathing suits or sweaters in a dressing room and then engaged in an arranged discussion with a female confederate in a neighboring stall. When engaging in fat talk, the female participants in the swimsuit condition had lower levels of negative emotions than those engaging in fat talk in the sweater condition. This suggests women might be more comfortable engaging in fat talk when they are expected to show concern about their bodies. 
Moreover, the act of engaging in fat talk may be significantly affected by conformity pressure. Indeed, Nichter and Vuckovic (1994) suggested that females utilize fat talk as a means of social acceptance by a valued group, a notion consistent with Asch's (1956) proposal that normative influence results from a desire to be accepted by a group and to avoid rejection. Individuals tend to avoid groups who reject them and desire inclusion in groups who accept them (Moscovici, 1976). When people are uncertain of being included, their actions may be determined by the desire to influence others and to secure social acceptance or avoid group ostracism (Pool \& Schwegler, 2007). Smith and Leaper (2006) suggested that females often base their self-worth on how well they fit the norm, and found that females often conform to social norms in order to elicit approval by other females. Some females may not want to engage in fat talk within a group, but may be unwilling to conflict with what most females see as the social norm, thus conforming to fat talk for a sense of collective well being. If women are aware of the social norm to fat talk when other women are doing so (as indicated by [Britton et al., 2006], [Nichter and Vuckovic, 1994] and [Smith and Leaper, 2006]), they may engage in these self-derogating dialogs because they believe that a failure to do so might result in social ostracism. Interestingly, this would suggest that fat talk was driven more by external pressures to conform than by internal dissatisfaction with one's body image.

Additionally, research suggesting gender differences in conformity provides further evidence that fat talk may be a function of feminine conformity. Eagly, Wood, and Fishbaugh (1981) arranged groups in which two males and two females shared their opinions on college campus issues in a written form and were informed that their opinions differed from the opinions given by the other group members. They provided opinions either with the knowledge that they would be shared with the other group members or kept private. They found that, overall, males tended to conform less than females. Further, females conformed more when participants were required to express their opinion under surveillance of the other group members, whereas males conformed less under surveillance. These results, as well as those of other studies investigating female public and private conformity ([Eagly and Chrvala, 1986], [Insko, 1983] and [Insko, 1985]) indicate that females want to be accepted by valued groups, as well as preserve social harmony, and may view conformity as a way to achieve these goals. Similarly, research by Santee and Jackson (1982) suggested females typically tend to think of conformity as positive and self-defining, whereas males believe they define themselves more when they are not conforming. 
Based on the previous research on conformity and gender identity, females may perceive fat talk as appropriate and conform to group fat talk because they see conformity to the group norm as appropriate and identifying. Nichter (2000) expanded on her initial research and found that some Caucasian middle school-aged girls would expect to be perceived by the group as conceited and to be judged as less likeable by their peers if they spoke positively about their bodies. Other research has shown that females are especially vulnerable to concerns about likeability due to the high value they place on female friendships and inclusion in social groups (Timmers, Fischer, \& Manstead, 1998).

Tucker, Martz, Curtin, and Bazzini (2007) examined the effect of social likeability and conformity in fat talk discussions through a dyadic conversation between female participants and a female confederate. While discussing opinions on one's own body appearance, the confederate either self-derogated by talking negatively about her body (rating her body a 0 on a scale of 10), self-accepted by conveying acceptance with her body appearance (rating her body a 6 out of 10), or self-aggrandized by reporting that she thought her body was very attractive (rating her body a 10 out of 10). Following the confederate's discussion, each participant was asked to discuss and rate her body. Results showed that participants' body ratings generally conformed to the confederate's ratings, as ratings of body image were lowest in the self-derogate condition, were moderate in the self-accept condition, and were highest in the self-aggrandize condition. Participants were also asked to privately rate the likeability of the confederate, which surprisingly did not vary according to the confederate's body presentation style. Notably, likeability of the confederate in that study could not be a function of conformity, as only the participant, not the confederate, was given the opportunity to conform.

Because research has shown that social desirability influences conformity, the current study employed a hypothetical group conversation to explore the possibility that fat talk, and its presumed opposite form of dialog-positive body talk, are a function of conforming to other females in order to be well-liked and accepted. We had research participants read one of four vignettes in which a group of young women engaged in positive or negative body talk (fat talk) and a target female ("Jenny") responded with either positive or negative body talk. Accordingly, the conditions differed in whether Jenny conformed to the group or not, and whether the group engaged in positive or negative body talk. In order to assess for differences between participants' personal opinions of likeability, and their expectations of other females' likeability judgments, we had participants rate how much they personally liked Jenny in addition to how likeable they expected the other members of the group to find Jenny. Based on the fat talk and 
conformity literature that both suggest females may engage in fat talk in order to be liked by other female group members ([Britton et al., 2006], [Eagly et al., 1981], [Eagly and Chrvala, 1986], [Insko, 1983], [Insko, 1985], [Nichter, 2000] and [Nichter and Vuckovic, 1994]), we predicted that Jenny would be most liked when she conformed to the group norm of negative body talk. As of yet, no literature has documented a norm for females to make self-accepting or positive statements about their bodies in a group setting. Thus, taking into account ethnographic research that suggested that young females think they will be disliked if they make accepting or positive statements about their bodies (Nichter, 2000), we expected that Jenny would be least liked by participants when she did not conform to the group's negative body talk, but instead made positive statements about her body. We expected likeability ratings in the remaining two conditions, in which Jenny either conformed or did not conform to the group's positive body talk, to be intermediate to the conditions in which Jenny responded to the group's negative body talk.

\section{Methods}

\section{Participants}

Female participants $(n=231)$ were recruited from the general psychology participant pool at a mid-sized, public, southeastern university. Sixteen were excluded because of missing data, resulting in a final sample of 215 participants. Their ages ranged from 17 to 24 with a mean of $18.8(S D=1.2)$. The sample was predominantly non-Hispanic, Caucasian $(n=198,92.1 \% ; n=8,3.7 \%$ African-American, $n=2,0.9 \%$ Hispanic, $n=2$, $0.9 \%$ Asian, $n=5,2.3 \%$ Other). The average Body Mass Index (BMI) was 23.3 (SD = 4.0 ), ranging from 16.6 to 44.6 . A one-way analysis of variance (ANOVA) indicated no significant differences on $\mathrm{BMI}$ among participants across the four conditions, $F(3,211)=$ $1.58, p=.20$, suggesting successful randomization to condition. Institutional Review Board (IRB) approval for this study was obtained June 1, 2007.

\section{Design}

The study employed a within- and between-subjects mixed design. There were two between-subjects variables (group presentation style: positive or negative and Jenny's presentation style: positive or negative) and one within-subjects variable (rating of likeability: personal or other). 


\section{Materials}

\section{Demographic information questionnaire}

A demographic questionnaire was used to obtain participants' age, ethnicity, and height and weight for BMI calculation, which was evaluated to ensure successful random assignment to condition across this dimension. Participants also completed a few other measures that were not evaluated in this research to serve as a distraction after reporting their body size prior to reading vignettes with body image discussions.

\section{Vignette}

Four different vignettes, all about a group of female college students of average weight studying for a biology exam, were used. Each vignette contained identical content except for the valence of the information that a designated female gave about a New Year's resolution related to her body image. This resulted in the positive or negative body talk manipulation. Two of the remaining group members responded to her comment by engaging in similar body talk; therefore, the first three members of the group all engaged in positive body talk (such as "I've been feeling pretty good about my body") or all engaged in negative body talk (such as "I've been feeling really fat lately"). All further content in the discussion on body image was consistent across the four vignettes except for the words that differentiated the group valence on body presentation style and Jenny's valence on her body image style response. Jenny was the final group member to discuss her body and she either conformed or did not conform to what the other group members said about their bodies with her own body image presentation. When the group members engaged in positive body talk, Jenny either conformed and stated, "I've been feeling good about my body. I don't need to go on a diet or anything," or did not conform and stated, "I've been feeling bad about my body. I should really go on a diet." Similarly, when the group members engaged in negative body talk, Jenny either conformed by responding, "l've been feeling bad about my body. I should really go on a diet," or did not conform, responding, "I've been feeling good about my body. I don't need to go on a diet or anything."

\section{Social attraction index}

A variation of Rudman's (1998) Social Attraction Index (SAI) was used to determine how much the participants liked Jenny $(k=6)$ and how likeable they expected the other members of the group to find Jenny $(k=4)$ after reading the vignette. 1 The 10 items on the SAI were rated on a 7 -point Likert scale $(1=$ not at all true, to $7=$ a great deal true) 
and the mean was used as the final score. Lower scores reflected a low level of social attractiveness, or likeability, and higher scores reflected a high level of social attractiveness. Cronbach's alpha was .90 for each of the SAI measures, suggesting adequate internal reliability.

\section{Procedure}

The study was run in a classroom of 25 participants at a time. Each participant privately completed a survey of demographic information and filler surveys, read his/her respective vignette (four conditions counter-balanced within each session), filled out the two versions of the SAI, and received extra credit for participation.

\section{Results}

A 2 (group body presentation style: positive or negative) $\times 2$ (Jenny's body presentation style: positive or negative) $\times 2$ (SAI ratings: personal vs. others) repeated measures ANOVA was conducted. Means and standard deviations across group presentation style, Jenny presentation style, and SAI ratings can be found in Table 1. Results showed that the SAI ratings of participants' personal liking of Jenny differed significantly from SAI ratings of participants' expectations of others' liking of Jenny, $F(1,211)=$ $24.83, p<.001$, such that personal ratings were higher than other ratings. This main effect was qualified by a significant three-way interaction, $F(1,211)=23.16, p<.001$, . The nature of this three-way interaction was investigated in multiple ways. First, post hoc paired t-tests were conducted to probe for differences between personal and other SAI ratings within each experimental condition. Then, individual ANOVAs were conducted separately for personal SAI ratings and other SAI ratings.

\begin{tabular}{|c|c|c|c|c|c|c|c|c|}
\hline \multirow[t]{3}{*}{ Group presentation } & \multicolumn{8}{|c|}{ Jenny presentation } \\
\hline & \multicolumn{4}{|c|}{ Negative } & \multicolumn{4}{|c|}{ Positive } \\
\hline & Mean & $S D$ & $\begin{array}{l}\text { Collapsed group } \\
\text { mean }\end{array}$ & Group $S D$ & Mean & $S D$ & $\begin{array}{l}\text { Collapsed group } \\
\text { mean }\end{array}$ & Group $S D$ \\
\hline \multicolumn{9}{|c|}{ SAI personal likeability } \\
\hline Negative & $4.48_{c e}$ & 1.15 & $4.48_{2}$ & 1.17 & $5.38_{c e}$ & 1.19 & $5.14 \mathrm{~b}$ & 1.08 \\
\hline Positive & $4.49_{\infty}$ & 1.21 & & & $4.88_{c e}$ & 0.90 & & \\
\hline \multicolumn{9}{|c|}{ SAI likeability by others } \\
\hline Negative & $4.55_{\propto}$ & 1.17 & $4.10_{2}$ & 1.17 & $4.37 \mathrm{dr}$ & 1.52 & $4.56 \mathrm{~b}$ & 1.37 \\
\hline Positive & $3.63 \pi$ & 0.97 & & & $4.77_{c e}$ & 1.16 & & \\
\hline
\end{tabular}


Note: Judgments are the mean of reported scores on a 7-point scale $(1=$ not at all, $7=$ a great deal $)$. Means across rows that do not share subscripts $a$ and $b$ represent a Jenny presentation style difference in the repeated measures ANOVA at $p<.05$. Means within each SAI dependent variable that do not share subscripts $c$ and $d$ represent an interaction between Group positive vs. negative presentation style and Jenny positive vs. negative presentation style at $p<.001$. Paired t-tests within each condition were used to compare across the SAI Likeability Personal and Others. Significant differences are indicated by e and $f$ subscripts, $p<.05$.

\section{Effect of presentational style on personal vs. other SAl ratings}

Individual paired t-tests were conducted to test for differences between personal and other SAI ratings within each of the four combinations of Jenny's and the group's presentational style. As Table 1 indicated, when both the group and Jenny were negative, $\mathrm{t}(56)=0.331, \mathrm{p}=.742$, and when both the group and Jenny were positive, $t(56)=-0.575, p=.568$, there were no differences in personal versus other SAl ratings (i.e., as delineated by shared "e" and "f" subscripts). Thus, when Jenny conformed, personal ratings were the same as perceived others' ratings of social likeability. However, participants' personal ratings of Jenny's likeability were higher than their expectations for how the group would rate her when Jenny did not conform to the group. Participants liked Jenny more than they thought the group would when the group was positive but Jenny was negative, $t(53)=-5.29, p<.001$, and when the group was negative and Jenny was positive, $t(54)=-6.11, p<.001$ (i.e., as shown with different "e" versus "f" subscripts).

\section{Effects of presentational style on personal SAI rating}

In order to explore the effects of Jenny's and the group's presentational style on participants' personal ratings of Jenny's likeability, a 2 (group presentation style: positive or negative) $\times 2$ (Jenny presentation style: positive or negative) ANOVA was conducted with personal SAI ratings as the dependent measure (see Table 1).

There was no evidence for a main effect of group presentation style, $F(1,211)=2.47, p$ $=.12$, but the main effect of Jenny's presentation style was significant, $F(1,211)=$ $17.70, p<.001$, (i.e., as indicated by different "a" and "b" subscripts on the collapsed group means and standard deviations). This indicates that participants gave higher personal SAI ratings when Jenny spoke positively about her body than when she spoke negatively. No interaction effect was observed between group presentation style and Jenny presentation style, $F(1,211)=2.84, p=.09$, , indicating that participants' 
personal preference for Jenny's positive body talk did not depend on whether she was conforming to the group or not.

\section{Effects of presentational style on other SAI ratings}

A $2 \times 2$ ANOVA was then computed with participants' SAI ratings of how likeable Jenny's group would find her as the dependent variable (Table 1). Similar to the previous ANOVA, results showed no main effect for group presentation style, $F(1,211)$ $=2.48, p=.12$. A main effect was observed, however, for Jenny's presentation style, $F(1,211)=8.23, p=.005$, such that participants thought the group would like her more when she spoke positively about her body than when she spoke negatively about her body (i.e., as indicated by different "a" and "b" subscripts on the collapsed group means and standard deviations). More importantly, there was a significant interaction between group presentation style and Jenny's presentation style, $F(1,211)=15.83, p<.001$, (i.e., as indicated by different "c" versus "d" subscripts). The interaction revealed that participants' expectations of how likeable the group would find Jenny depended on whether her body talk matched their own. Specifically, participants expected that when the group engaged in negative body talk, they would like Jenny equally well whether she responded with positive or negative body talk, $t(109)=0.72, p=.47$. However, when the group engaged in positive body talk, participants expected that her group would find Jenny significantly more likeable if she also spoke positively about her body than if she responded with negative body talk, $\mathrm{t}(102)=-5.47, \mathrm{p}<.001$ (i.e., as indicated by different "c" versus "d" subscripts). Equivalently, participants expected that when Jenny spoke positively about her body, her group would like her equally well regardless of their own body talk, $t(102)=-1.51, p=.13$. However, participants expected that when Jenny spoke negatively about her body in the context of the group's positive body talk, the group would like her less than if she spoke negatively in the context of the

group's own negative body talk, $\mathrm{t}(108)=4.50, \mathrm{p}<.001$ (i.e., as indicated by different "c" versus "d" subscripts). While an interaction between group presentation style and Jenny's presentation style was predicted, the nature of the interactive effect was inconsistent with the hypothesis that Jenny would be found most likeable when conforming to negative body talk and least likeable when speaking positively about herself in the context of the group's negative body talk.

\section{Effects of BMI on likeability ratings}

Considering the possibility that the BMI of participants might have affected likeability ratings of Jenny, the correlation between $\mathrm{BMI}$ and $\mathrm{SAI}$ ratings was examined. Participants' BMI did not relate to Other SAI ratings (i.e., participants' expectations of 
how likeable the group would find Jenny), $r=-.030, p=.661$. However, there was a slight relationship between participants' BMI and their personal liking of Jenny, $r=.288$, $p<.001$, indicating that larger participants tended to like Jenny slightly more. Recall however, that BMI did not differ across the experimental conditions, so this relationship does not account for the differences in Jenny's likeability across conditions.

\section{Discussion}

The current study utilized vignettes of a target female, who either conformed or did not conform to a same-sex group's positive or negative body talk, in order to assess whether perceptions of her social likeability varied as a function of that conformity. The hypotheses of this study, primarily that Jenny would be least liked when she engaged in positive body talk following the group norm of negative body talk, and would be most liked when conforming to negative body talk, or to the fat talk norm, were not supported. Contrary to previous literature suggesting that conforming to fat talk is normative among young American women ([Britton et al., 2006] and [Nichter and Vuckovic, 1994]), our results demonstrated evidence for a surprising deviation from this trend. First of all our direct comparisons between the ratings of personal likeability and others' likeability of Jenny within each experimental condition found that Jenny's personal likeability was higher than that of perceived others when she failed to conform to the group discussion but were similar when Jenny conformed.

When personal ratings and others' ratings were separated by individual analyses, more intricate results emerged. When participants were rating the likeability of Jenny based on their personal opinions, they liked Jenny more when she spoke positively about her body, regardless of the body presentation style of the group. By contrast, participants expected the other group members in the vignette to see Jenny as more likeable when she conformed to the group's body presentation style, particularly when the group's body talk was positive. As of yet, there has been no research documenting reasons for why females find body acceptance more appealing than body derogation, making these results of particular interest.

Similar to the study by Britton et al. (2006), these findings demonstrate that females may believe that their personal opinions differ from the perceived opinions of other females. They found that although females judged themselves to be unlikely to engage in fat talk in a group setting, they expected that other females would conform to fat talk within the group. These findings, along with results of the current study, indicate that 
females consider themselves less prone than others to engage in behaviors which perpetuate the fat talk norm. Research in the field of communication has identified what is likely a comparable phenomenon, termed the "third-person effect," in which the self is seen as less likely than others to be persuaded by negative media influence ([Davison, 1983] and [Terry et al., 1999]). David and Johnson (1998) found body image was not immune to the third-person effect, as females judged their female peers to be significantly more susceptible than themselves to negative media effects on perception of ideal body weight, self-esteem, and development of eating disorders. Or this may be a function of the "above-average effect" or the tendency for individuals to view themselves as better than average on characteristics that are socially desirable (Alicke, 1985). In this case, the above-average effect might suggest that females believe that behaviors perpetuating the fat talk norm are not as attractive as behaviors of selfacceptance.

Alternatively, though females may believe that they should reject the fat talk norm as well as the cultural media emphasis on female beauty, it may be more difficult to resist body objectification when confronted with the choice between body acceptance and body objectification in real circumstances. In a study on feminist women's body consciousness, Rubin, Nemeroff, and Russo (2004) designed focus group discussions among women with feminist beliefs. Many participants revealed that, despite holding the belief that females should accept their bodies and reject the media's emphasis on body appearance, they often personally experienced body dissatisfaction. Several participants reported feeling self-conscious about their bodies in objectifying situations such as shopping, going to clubs, and walking in public. Therefore, it is possible that the participants in this study held the belief that females should promote body acceptance, and thus rated Jenny higher when she spoke positively about her body, but might engage in body derogation when confronted with body objectification in a real situation.

The fact that our results deviated from previous fat talk findings is intriguing. Nichter and Vuckovic (1994) documented that females think they engage in fat talk as a method of impression management and to avoid social rejection, and Nichter (2000) later found that middle school-aged girls thought that they engaged in fat talk discussions so as not to be perceived by the group as conceited, and consequently be judged as less likeable by their peers. Though Tucker et al. (2007) did not find that body aggrandizement decreased social likeability, results demonstrated a significant conformity of female participants to the body presentation style of a confederate. Comparisons of the current study to Tucker et al.'s study are limited in nature due to the differences in methodology; most notably that the current study used a hypothetical vignette depicting a group 
situation of conformity, while Tucker et al. arranged an actual dyadic conversation. However, despite Tucker et al.'s findings and other research indicating that women engage in public conformity more often than men ([Eagly et al., 1981], [Eagly and Chrvala, 1986], [Insko, 1983] and [Insko, 1985]), possibly due to a strong desire for inclusion in social groups (Timmers et al., 1998), the current findings demonstrate a surprising new trend in female interactions relating to body image. In this study, women judged a target woman to be more likeable when she engaged in positive body talk and judged her to be less likeable when she engaged in fat talk following a group discussion of positive body talk, despite her conformity to the fat talk norm. Thus, despite women's awareness of social expectations about fat talk, a competing norm to express selfacceptance of one's body may be preexisting or emerging among women.

Strahan et al. (2008) identified a frequent sociocultural "predicament" for women, in which they must choose between protecting themselves from the threat of social rejection by engaging in talk that expresses a desire to appear like the ideal female portrayed by the media, or abandoning the beauty ideal at the risk of social rejection in order to gain independence and self-acceptance. This predicament may be explained by a larger conflict between different standards within American women's cultural worldviews. The traditional gender imperative represents American women as inclusive within groups, communal, caring, and nurturing (Jost \& Kay, 2005); however, a new American worldview, especially appropriate in American colleges, emphasizes independence and uniqueness (Crocker, Luhtanen, Cooper, \& Bouvrette, 2003; Markus \& Kitayama, 1991). Inclusion and uniqueness may be competing motives for women in contemporary society (Simon et al., 1997), especially promoted by the new occupational and independence opportunities that have been afforded to women in the past few decades (Novack \& Novack, 1996).

Concurrently, as the media increases its efforts to promote body acceptance, perhaps women are feeling less bound by the "predicament" proposed by Strahan et al. (2008) and are becoming comfortable with the idea of speaking positively about their bodies. Though research has not documented such a shift in female mindset, advertising initiatives such as the Dove Campaign for Real Beauty, which began in 2004, have promoted body acceptance throughout the media and seem to be challenging the previous fat-talk norm in favor of publicly accepting one's body. Importantly, however, such media efforts are few in comparison to the cultural emphasis on beauty that remains pervasive through U.S. media. The current study suggests that women may have less positive views of other women who engage in negative body talk, signifying that the rising American view of valuing independence and individuality in women may 
be challenging traditional female views about weight and those that endorse those views. Though it has been shown that college students believe that men prefer women who accept their bodies, yet believe that other women would find those who selfderogate their bodies as most socially attractive (Britton et al., 2006), this is the first study to demonstrate that fat talk in certain situations may prove to be a social liability for women.

In addition to an indication of competing norms regarding body image, this study suggests fat talk is not simply a function of conformity. That is, women personally found positive body talk as likeable, regardless of what other group members said about their bodies, even though participants acknowledged that other women would not find the non-conforming woman as likeable as they thought they would. Women appear to be aware of the norm to engage in fat talk (Britton et al., 2006) and feel as if it is more appropriate to objectify one's body in situations where body image is salient (Gapinski et al., 2003), but do not appear to perceive body objectification as expected or necessary.

\section{Limitations}

Despite indications of a possible competing self-accepting social norm compared to the norm to fat talk in women's dialogs, the conclusions of this study must be interpreted in light of its potential limitations. Use of a hypothetical vignette of a female conversation, though simple to manipulate, sacrificed external validity and generalizability of the results. Fat talk occurs in social situations (Nichter \& Vuckovic, 1994) and judgments of social likeability are generally made from social interactions with others, in contrast to a judgment made on the basis of a written conversation. In addition, judgments of likeability are generally not made on the basis of a sole factor, but are a composite judgment formed by conversation, physical appearance of the target, and other variables. As participants could not view the conversation in real-time and make judgments that were not based on actual ecological variables, they could have had a possible bias in likeability ratings. Moreover, we failed to include a manipulation check asking participants their presumed image of Jenny, especially her presumed body size. Perhaps their personal likeability ratings and how much they thought others liked her interacted across conditions as a function of presumed appearance of Jenny. Overall however, the use of an experimentally manipulated vignette allowed for improved internal validity, providing a method in which cause and effect conclusions were more possible. 
With regard to the experimental manipulation between types of body talk, employing a "no body talk" condition in which the target group member changed the topic of discussion away from body talk might have revealed whether participants preferred females that did not choose to continue a discussion of body talk. However, this type of non-conformity from the group norm would not be in direct contrast to the "conform" conditions and would not provide the same social risk of rejection that has been discussed by Nichter (2000). Therefore, the current study sought to examine the effect on social likeability of conformity and non-conformity by the target member engaging in the type of body talk either similar to or opposite of the group. Notably, the "positive body talk" condition may not have represented true body acceptance; the target female did not specify that she had accepted her body regardless of its size, but simply indicated an acceptance of her current body size. Future research will want to examine more closely reactions to different forms of body talk, conversational diversions from such talk, and the effect on social likeability of the rejection of both weight concerns and self-objectification.

Participants' personal ratings of the target woman's likeability could have been affected by demand characteristics, social desirability bias, or the "third-person effect" (Davison, 1983). However, if participants attempted to portray themselves as straying from the fat talk norm, this implies that the participants found resisting the fat talk norm to be socially desirable, further supporting the results of this study that suggest the existence of competing norms. This resistance of the fat talk norm, which may be seen as socially desirable, is similar to the results previously described in Rubin et al.'s (2004) study on body consciousness. Indeed, participants in her focus groups revealed that they experienced body objectification and dissatisfaction, regardless of their belief that women should reject the fat talk norm and the media's emphasis on beauty.

Notably, no manipulation check was used as part of the study to ensure that participants were making social likeability ratings based on whether Jenny conformed or did not conform to the group's body talk or if they were basing their opinions on other cues in the vignettes. All participants in the current study were college-aged, primarily Caucasian, females. The extant fat talk research does not demonstrate whether or not males would respond in the same way as the females in the current study; therefore, a study investigating the effects of conformity to body presentation style on males' judgment of females' likeability could add to the current research base. Additionally, recent research has shown that males are not immune to the media's emphasis on beauty; in fact, males who feel as if they should look similar to muscular men in the media have been shown to have decreased body dissatisfaction and body esteem 
([Agliata and Tantleff-Dunn, 2004] and [Bartlett et al., 2005]). Therefore, a study on the pressure and prevalence of fat talk in men would be a substantial contribution to the research literature. In addition, based on the homogeneity of study participants, the results cannot be generalized to all women. Developmental differences in social likeability judgments could vary by age and ethnicity, thus, different results may be found for females in adolescence as well as for women throughout adulthood or when examining body talk perceptions among women of varied races. Perhaps by the time women surpass adolescence, they experience a change in body image opinions, appreciating positive body talk more than would middle school-aged girls who were the focus of research by Nichter and Vuckovic (1994). As women mature and begin to form an identity based on uniqueness and independence ([Crocker et al., 2003] and [Markus and Kitayama, 1991]), it might become more socially attractive for them to accept their bodies personally and publicly, especially while attending college ([Crocker et al., 2003] and [Markus and Kitayama, 1991]). Cross-cultural research could also demonstrate various results, as research has focused on typical American views and has not investigated how body image norms and social desirability interact in other cultures.

This was the first study to investigate whether conformity or nonconformity in fat talk situations affect judgments of social likeability. Considering its methodological limitations, future research should focus on experimentally manipulating real-time conversations with the use of confederates to produce more realistic and generalizable results. Research using such realistic conversations could also examine the effect of the target woman's body size on their resulting social attractiveness. Expected congruence and incongruence between body presentation style and actual body weight might have different effects on social likeability, with participants hypothetically disliking women who appear to be of normal weight but who express dissatisfaction with their bodies. In this research, it would be important to assess for the relationship between the target woman's physical attractiveness and body size and to examine the effects of physical attractiveness on social likeability, as it is possible for physical attractiveness to have a greater effect on social likeability than congruence between body size and body presentation style (Dion, Berscheid, \& Walster, 1972). For example, Davis-Pyles, Conger, and Conger (1990) found that overweight women were considered to have fewer social skills, as well as be less likeable, friendly, attractive, and intelligent than either average weight or underweight women in the workplace. However, when their attractiveness was controlled, the reported differences in social skills were eliminated.

As the current study resulted in surprising evidence of competing norms between fat talk and the expression of body acceptance, future research should focus more on body 
acceptance and the potential appreciation and admiration of a confident woman ([Crocker et al., 2003] and [Markus and Kitayama, 1991]). Researchers may also seek to discriminate between women's perception of self-acceptance as socially desirable versus perceiving resistance against societal norms as socially desirable. Through resistance to norms, women might be expressing their dissatisfaction with unrealistic societal ideals of beauty. On the other hand, if further investigation finds that selfacceptance does, in fact, lead to social desirability, dissemination of such information could help promote "body acceptance" among America's women. This changing norm might increase women's self-esteem in addition to their body esteem, and may decrease the risk for severe body dissatisfaction that often leads to eating disorders.

\section{Conclusions}

Research remains scarce on the effect of fat talk and conformity on social likeability, but like Britton et al. (2006), this study found evidence for a third-person effect in body image conversations with additional implications. First, women may not find themselves as susceptible to less positive likeability judgments on women who refrain from engaging in the fat talk norm than initially thought. Second, women appear to be subject to a changing norm emphasizing positive body talk and acceptance of one's body, suggesting that fat talk is not simply conformity to a group in order to be well liked. Recent social and feminist trends in America seem to be pushing for increased body acceptance and overall self-acceptance, and these efforts appear to be having an impact. Finally, it can be concluded that future research is necessary to clarify the competing body talk norms in today's society.

\section{References}

Agliata and Tantleff-Dunn, 2004 D. Agliata and S. Tantleff-Dunn, The impact of media on males' body image, Journal of Social and Clinical Psychology 23 (2004), pp. 7-22.

Alicke, 1985 M.D. Alicke, Global self-evaluation as determined by the desirability and controllability of trait adjectives, Journal of Personality and Social Psychology 49 (1985), pp. 1621-1630. 
Asch, 1956 S.E. Asch, Studies in independence and conformity: A minority of one against a unanimous majority, Psychological Monographs 70 (Whole no. 416) (1956).

Bartlett et al., 2005 C.P. Bartlett, R.J. Harris, S. Smith and J. Bonds-Raacke, Action figures and men, Sex Roles 53 (2005), pp. 877-885.

Britton et al., 2006 L.E. Britton, D.M. Martz, D.G. Bazzini, L. Curtin and A. LeaShomb, Fat-talk and self-presentation of body image: Is there a social norm for women to selfdegrade?, Body Image 3 (2006), pp. 247-254.

Clark and Tiggemann, 2006 L. Clark and M. Tiggemann, Appearance culture in nine- to 12-year-old girls: Media and peer influences on body dissatisfaction, Social Development 15 (2006), pp. 628-643.

Crocker et al., 2003 J. Crocker, R.K. Luhtanen, M.L. Cooper and A. Bouvrette, Contingencies of self-worth in college students: Theory and measurement, Journal of Personality and Social Psychology 85 (2003), pp. 894-908.

David and Johnson, 1998 P. David and M.A. Johnson, The role of self in third-person effects about body image, Journal of Communication 48 (1998), pp. 37-58.

Davis-Pyles et al., 1990 B. Davis-Pyles, J.C. Conger and A.J. Conger, The impact of deviant weight on social competence ratings, Behavioral Assessment 12 (1990), pp. 443-455.

Davison, 1983 W.P. Davison, The third-person effect in communication, Public Opinion Quarterly 47 (1983), pp. 1-15. 
Dion et al., 1972 K. Dion, E. Berscheid and E. Walster, What is beautiful is good, Journal of Personality and Social Psychology 24 (1972), pp. 285-290.

Eagly and Chrvala, 1986 A.H. Eagly and C. Chrvala, Sex differences in conformity: Status and gender role interpretations, Psychology of Women Quarterly 10 (1986), pp. 203-220.

Eagly et al., 1981 A.H. Eagly, W. Wood and L. Fishbaugh, Sex differences in conformity: Surveillance by the group as a determinant of male nonconformity, Journal of Personality and Social Psychology 40 (1981), pp. 384-394.

Gapinski et al., 2003 K.D. Gapinski, K.D. Brownell and M. LaFrance, Body objectification and "fat talk": Effects of emotion, motivation, and cognitive performance, Sex Roles 48 (2003), pp. 377-388.

Grogan et al., 1996 S. Grogan, Z. Williams and M. Conner, The effects of viewing same-gender photographic models on body esteem, Psychology of Women Quarterly 20 (1996), pp. 569-575.

Insko, 1983 C.A. Insko, Conformity as a function of the consistency of positive selfevaluation with being liked and being right, Journal of Experimental Social Psychology 19 (1983), pp. 341-358.

Insko, 1985 C.A. Insko, Conformity and group size: The concern with being right and the concern with being liked, Personality and Social Psychology Bulletin 11 (1985), pp. $41-50$.

Jost and Kay, 2005 J.T. Jost and A.C. Kay, Exposure to benevolent sexism and complementary gender stereotypes: Consequences for specific and diffuse forms of system justification, Journal of Personality and Social Psychology 88 (2005), pp. 498509. 
Krones et al., 2005 P.G. Krones, E. Stice, C. Batres and K. Orjada, In vivo social comparison to a thin-ideal peer promotes body dissatisfaction: A randomized experiment, International Journal of Eating Disorders 38 (2005), pp. 134-142.

Markus and Kitayama, 1991 H.R. Markus and S. Kitayama, Culture and the self: Implications for cognition, emotion, and motivation, Psychological Review 98 (1991), pp. 224-253.

Moscovici, 1976 S. Moscovici, Social influence and social change, Academic Press Inc., New York (1976).

Nichter, 2000 M. Nichter, Fat talk: What girls and their parents say about dieting, Harvard University Press, Cambridge, MA (2000).

Nichter and Vuckovic, 1994 M. Nichter and N. Vuckovic, Fat talk. In: N. Sault, Editor, Many mirrors: Body image and social relations, Rutgers University Press, New Brunswick, NJ (1994), pp. 109-131.

Novack and Novack, 1996 L.L. Novack and D.R. Novack, Being female in the eighties and nineties: Conflicts between new opportunities and traditional expectations among White, middle class, heterosexual college women, Sex Roles 35 (1996), pp. 57-78.

Pool and Schwegler, 2007 G.J. Pool and A.F. Schwegler, Differentiating among motives for norm conformity, Basic and Applied Social Psychology 29 (2007), pp. 47-60

Rodin et al., 1984 J. Rodin, L. Silberstein and R. Striegel-Moore, Women and weight: A normative discontent, Nebraska Symposium on Motivation 32 (1984), pp. 267-307. 
Rubin et al., 2004 L.R. Rubin, C.J. Nemeroff and N.F. Russo, Exploring feminist women's body consciousness, Psychology of Women Quarterly 28 (2004), pp. 27-37.

Rudman, 1998 L.A. Rudman, Self-promotion as a risk factor for women: The costs and benefits of counterstereotypical impression management, Journal of Personality and Social Psychology 74 (1998), pp. 629-645.

Santee and Jackson, 1982 R.T. Santee and S.E. Jackson, Identity implications of conformity: Sex differences in normative and attributional judgments, Social Psychology Quarterly 45 (1982), pp. 121-125.

Schlenker, 1985 B.R. Schlenker, Identity and self-identification. In: B.R. Schlenker, Editor, The self and social life, McGraw-Hill, New York (1985), pp. 65-69.

Simon et al., 1997 L. Simon, J. Greenberg, J. Arndt, T. Pyszczynski, R. Clement and S. Solomon, Perceived consensus, uniqueness, and terror management: Compensatory responses to threats to inclusion and distinctiveness following mortality salience, Personality and Social Psychology Bulletin 23 (1997), pp. 1055-1065.

Smith and Leaper, 2006 T. Smith and C. Leaper, Self-perceived gender typicality and the peer context during adolescence, Journal of Research on Adolescence 16 (2006), pp. 91-103.

Strahan et al., 2008 E.J. Strahan, A. Lafrance, A.E. Wilson, N. Ethier, S.J. Spencer and M.P. Zanna, Victoria's dirty secret: How sociocultural norms influence adolescent girls and women, Personality and Social Psychology Bulletin 34 (2008), pp. 288-301.

Terry et al., 1999 D.J. Terry, M.A. Hogg and J.M. Duck, Group membership, social identity, and attitudes. In: D. Abrams and M.A. Hogg, Editors, Social identity and social cognition, Blackwell Publishing, Malden, MA (1999), pp. 280-314. 
Timmers et al., 1998 M. Timmers, A. Fischer and A. Manstead, Gender differences in motives for regulating emotions, Personality and Social Psychology Bulletin 24 (1998), pp. 974-985.

Tucker et al., 2007 K.L. Tucker, D.M. Martz, L.A. Curtin and D.G. Bazzini, Examining 'fat talk' experimentally in a female dyad: How are women influenced by another woman's body presentation style?, Body Image 4 (2007), pp. 157-164. 